\title{
High-resolution esophageal manometry: A time motion study
}

\author{
Daniel C Sadowski MD FRCPC ${ }^{1}$, Linda Broenink RN ${ }^{2}$
}

DC Sadowski, L Broenink. High-resolution esophageal manometry: A time motion study. Can J Gastroenterol 2008; 22(4):365-368.

INTRODUCTION: High-resolution manometry (HRM) of the esophagus is a new technique that provides a more precise assessment of esophageal motility than conventional techniques. Because HRM measures pressure events along the entire length of the esophagus simultaneously, clinical procedure time should be shorter because less catheter manipulation is required. According to manufacturer advertising, the new HRM system is more accurate and up to $50 \%$ faster than conventional methods.

OBJECTIVE: To test the hypothesis that clinical testing with HRM requires less procedural time than a standard water perfusion (WP) method.

METHODS: Forty-one consecutive patients were studied (20 underwent WP and 21 underwent HRM). Using time-motion analysis, the start and end times for each task associated with performing the study were recorded. Patient discomfort and study quality were also assessed by using five- and four-point qualitative scales, respectively.

RESULTS: Total procedure time was reduced on average by $25.6 \%$ in the HRM group (from 41.8 minutes with WP to 30.7 minutes with HRM, $\mathrm{P}<0.05)$. There was no significant difference in the discomfort scores reported by the study subjects and no difference in study quality.

CONCLUSIONS: HRM requires less time to complete than conventional manometry and should therefore shorten the wait-times of patients scheduled for esophageal manometry and have a significant impact on the cost of performing this commonly used clinical investigation.

Key Words: Esophageal manometry; Time-motion analysis

\section{Manométrie œsophagienne haute résolution : Analyse temps-mouvement}

INTRODUCTION : La manométrie haute résolution (MHR) de l'œsophage est une nouvelle technique qui permet une évaluation plus précise de la motilité œsophagienne comparativement aux techniques habituelles. Étant donné que la MHR mesure simultanément les variations de pression sur toute la longueur de l'œesophage, l'intervention clinique devrait être plus brève, puisqu'il n'est pas nécessaire de manipuler autant le cathéter. Selon la publicité du fabricant, le nouveau système de MHR est plus précis et jusqu'à $50 \%$ plus rapide que les méthodes habituelles.

OBJECTIF : Vérifier l'hypothèse selon laquelle les tests cliniques par MHR requièrent moins de temps que la méthode habituelle avec perfusion d'eau.

MÉTHODE : Quarante-et-un patients consécutifs ont subi le test (20 par perfusion d'eau et 21 par MHR). À l'aide d'une analyse temps-mouvement, l'heure du début et de la fin de chaque étape de l'examen a été enregistrée. L'inconfort du patient et la qualité des résultats ont aussi été mesurés à l'aide d'échelles qualitatives en cinq et quatre points, respectivement.

RÉSULTATS : La durée totale de l'intervention a diminué en moyenne de 25,6\% dans le groupe sous MHR (41,8 minutes avec perfusion d'eau et 30,7 minutes avec la MHR, p < 0,05). On n'a noté aucune différence significative quant à l'inconfort déclaré par les patients de l'étude et aucune différence quant à la qualité des résultats obtenus.

CONCLUSION : La MHR requiert moins de temps que la manométrie standard; elle devrait par conséquent abréger les temps d'attente pour les patients qui doivent subir cet examen de l'œsophage et réduire significativement le coût de cette épreuve clinique d'usage courant.
Csophageal manometry provides both quantitative and qual$\mathrm{C}_{\text {itative measurements of esophageal pressure and peristaltic }}$ coordination. Common clinical indications for this procedure include motor-type dysphagia assessment, intraluminal device placement and preoperative assessment of candidates for antireflux surgery (1). Despite the fact that pressure recordings from the esophagus have been obtained for more than 100 years, considerable methodological variations exist between motility laboratories. Most commonly, either waterperfused catheters or solid-state pressure transducer systems are used for clinical diagnosis. Commercially manufactured catheters are available for both methods and are usually configured with four to eight recording sites spaced at regular intervals along the catheter length. This arrangement requires substantial catheter manipulation during the procedure to sequentially place the recording sites in areas of interest such as the lower esophageal sphincter (LES). A working group recently attempted to standardize the performance and interpretation of esophageal manometry (2).

An ideal manometric system would acquire continuous, high-fidelity pressure data from the pharynx to the stomach with circumferential sensitivity. For patient comfort, the procedure should be quick and easy to perform (3). To meet these objectives, high-resolution manometry (HRM) was developed. A commercially available high-resolution catheter has 36 solidstate circumferential sensors spaced at $1 \mathrm{~cm}$ intervals along the entire intracorporal portion of the catheter assembly (Sierra Scientific Instruments, USA). This arrangement facilitates pressure assessment of the entire esophagus, from the cricopharyngeus to the LES, without the need for catheter pull-through manoeuvres. In concert with catheter development are advances in data acquisition software, which allow

${ }^{1}$ Division of Gastroenterology, Royal Alexandra Hospital; ${ }^{2}$ Gastrointestinal Motility Laboratory, Walter C MacKenzie Health Sciences Centre, Edmonton, Alberta

Correspondence: Dr Daniel C Sadowski, Division of Gastroenterology, Room 331, Community Services Centre, Royal Alexandra Hospital,

Edmonton, Alberta T5H 3V9. Telephone 780-735-6837, fax 780-735-5650, e-mail dan.sadowski@ualberta.ca

Received for publication October 17, 2007. Accepted November 26, 2007 


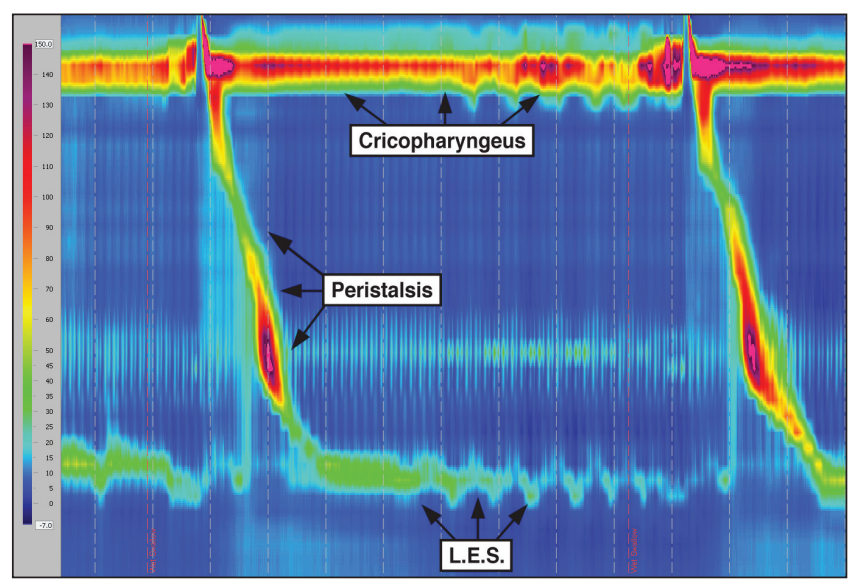

Figure 1) Spatiotemporal plot obtained during high-resolution manometry depicting esophageal pressure activity from the pharynx to the stomach. LES Lower esophageal sphincter

for the construction of spatiotemporal plots. These plots create an intuitive graphical running display of pressure events over the entire esophagus, thus allowing for rapid interpretation and diagnosis (Figure 1). Normal values for high-resolution studies have recently been described (4). Early clinical studies have suggested that HRM is superior to standard manometry methods in detecting clinical abnormalities such as unsuccessful esophageal bolus transport (5). According to manufacturer advertising, HRM is simpler and more precise than older methods. Also, a $50 \%$ reduction in procedure time is suggested (6). Because procedure time is directly related to costs, patient comfort and wait times, we sought to test the hypothesis that HRM of the esophagus will require less procedure time than a standard water perfusion (WP) method during routine clinical use.

\section{PATIENTS AND METHODS}

The study subjects consisted of 41 patients referred to the Gastrointestinal Motility Laboratory at the University of Alberta Hospital (Edmonton, Alberta) for investigation with esophageal manometry. An intended conversion in the laboratory from the WP method to the HRM system provided a unique opportunity to observe the HRM system's impact on procedure time. Written informed consent was obtained from all subjects. The first 20 studies were performed on consecutive patients using a WP method (Appendix 1). Twenty-one studies were then performed on consecutive patients using HRM (Appendix 2). All study procedures were performed by the same motility nurse who had previously performed more than 1000 esophageal motility procedures. Before beginning the HRM portion of the study, the nurse familiarized herself with the HRM system by attending a training course and performing approximately 10 clinical studies under supervision (data not included in the analysis).

Using time-motion analysis, the start and end times of each task associated with performing the esophageal manometry study were recorded with a stopwatch. The five specific tasks were initial patient assessment and nasal anesthesia; machine and catheter set-up; manometry procedure (from catheter intubation to removal from the patient); catheter cleaning; and data analysis.

At the conclusion of the procedure, the patient was asked to rate the level of discomfort using a five-point scale $(1-$ no
TABLE 1

Patient characteristics

\begin{tabular}{lcc}
\hline & \multicolumn{2}{c}{ Manometry type } \\
\cline { 2 - 3 } Variable & 20 & High resolution \\
\hline Patients, $\mathrm{n}$ & $5: 15$ & 21 \\
Male:female & 46 & $6: 15$ \\
Mean age, years & & 52 \\
Indication, $\mathrm{n}$ & 7 & \\
$\quad$ GERD (pH probe placement) & 9 & 13 \\
Dysphagia & 1 & 4 \\
Preoperative assessment & 3 & 0 \\
Other & & 4 \\
Diagnosis ${ }^{*}, \mathrm{n}$ & 9 & \\
Low LES pressure & 4 & 10 \\
Hiatus hernia & 3 & 4 \\
Normal & 5 & 2 \\
Ineffective motility & 1 & 0 \\
Achalasia & &
\end{tabular}

*Some patients had more than one diagnosis. GERD Gastroesophageal reflux disease; LES Lower esophageal sphincter

discomfort; 2 - mild discomfort; 3 - moderate discomfort; 4 - high level of discomfort; and 5 - extreme discomfort) (7). The physician analyzing the study data rated the quality of each tracing using a four-point scale $(1-$ manometric tracings were insufficient to provide any meaningful diagnosis; 2 - sufficient manometric data were available to provide at least a partial diagnosis, although there was significant uncertainty; 3 - sufficient data were present to provide a complete manometric diagnosis with minimal uncertainty; and 4 - excellent manometric data were available to provide a clinically certain diagnosis). The results for each patient were entered into a computer spreadsheet and mean values were compared using Student's $t$ test.

\section{RESULTS}

The characteristics of the study subjects are presented in Table 1. There were no incomplete HRM or WP procedures. The principal finding was that the average total procedure time was reduced using the HRM method by $25.6 \%$. The mean time for WP was $41.8 \mathrm{~min}$ (range $36 \mathrm{~min}$ to $48 \mathrm{~min}$ ) compared with $30.7 \mathrm{~min}$ (range $22 \mathrm{~min}$ to $39 \mathrm{~min}$ ) using the HRM method $(\mathrm{P}<0.05)$. As expected, no significant difference in time duration of WP versus HRM was required for the initial patient assessment phase of the procedure (16.6 min versus $13.8 \mathrm{~min}$, respectively) and therefore, these data were not included in the final totals. For each of the other procedurerelated tasks, a significantly shorter period of time was required for HRM, including set-up time (Figure 2). The largest reduction in task time was seen in the time from catheter intubation to removal. In this phase of the procedure, the mean time for WP was $22.1 \mathrm{~min}$ (range $18 \mathrm{~min}$ to $29 \mathrm{~min}$ ) compared with $16.6 \mathrm{~min}$ (range $10 \mathrm{~min}$ to $26 \mathrm{~min})$ for HRM $(\mathrm{P}<0.002)$. This reduction in time was primarily realized because LES pullthrough manoeuvres were not required in the HRM method, and would probably not be realized in motility laboratories that use the Dent sleeve method of manometry. There were no significant differences in the discomfort scores reported by the 
study subjects (2.0 versus 2.4 for WP versus HRM, respectively). There were no significant differences in study quality scores between the two methods (3.4 versus 3.6 for WP versus HRM, respectively).

\section{DISCUSSION}

New diagnostic technology for clinical care is adopted if the latest method is safer, more accurate or less expensive than a currently used procedure (8). In terms of diagnostic accuracy, HRM has been found to be superior to older methods for measuring esophageal bolus transit, hiatus hernia size and transient LES relaxations $(5,9)$. Also, the close spatial configuration of the pressure sensors allows for routine assessment of previously difficult structures such as the cricopharyngeus muscle and the crural diaphragm $(10,11)$. In our investigation, we identified a significant reduction in procedural time without compromising patient safety, comfort or study quality. However, it should be noted that due to the constraints of study design, it was not possible to perform blinded assessments of patient comfort and study quality, and there was a potential for observer bias.

In the current Canadian health care environment, costs and patient access to clinical care are of particular concern. A $25 \%$ reduction in procedure time with the use of HRM was observed in the present study, which could potentially shorten wait-times of patients scheduled for esophageal manometry. In terms of cost, esophageal manometry has three main economic drivers: capital equipment, consumable costs and nonconsumable costs. Consumable costs mainly relate to expenditures for catheter replacement while nonconsumable costs arise mainly from overhead charges (eg, staff salaries). WP manometry has relatively inexpensive capital equipment and consumable costs but requires significant staff training and has a relatively long procedure time (12). A WP system, including analysis software, can be purchased in Canada for under $\$ 25,000$. WP catheters, depending on the configuration, cost less than $\$ 500$ each and, in our experience, can be used for up to 300 studies. In contrast, HRM has a high capital and consumable cost, but a shorter procedure time and a reduced requirement for staff training. For a high-resolution system, hardware costs are approximately $\$ 70,000$. Each catheter currently costs $\$ 13,000$ and, in our experience, can be used for approximately 300 studies. We found that a previously experienced motility nurse was able to achieve competence with the HRM system after performing 10 clinical studies. Further analysis is required to determine the precise economic trade-offs between HRM and conventional techniques.

\section{CONCLUSIONS}

HRM requires less procedure time than WP manometry, without a corresponding increase in patient discomfort or reduction in study quality. This fact, along with the increased accuracy of HRM, should pave the way for widespread adoption of this technological advance.

\section{APPENDIX 1 - ESOPHAGEAL MANOMETRY STUDY: WP METHOD}

\section{Preprocedural assessment}

Each subject underwent a brief clinical interview and was taught about the procedure. Informed consent was obtained. One nostril was anesthetized using Xylocaine 2\% jelly (AstraZeneca Canada Inc, Canada).

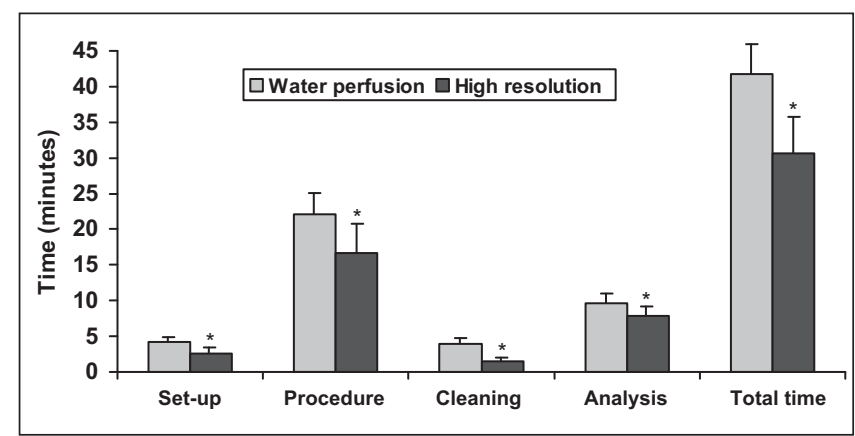

Figure 2) Time required for specific steps in esophageal manometry using either a water perfusion or a high-resolution method. $* P<0.05$

\section{Equipment set-up}

WP studies were performed using an electric perfusion manometric pump (Mui Scientific, Canada) and catheters that were constructed of medical-grade polyvinyl chloride tubing with eight perfusion side holes spaced along the catheter length at regular intervals.

1. The catheter perfusion ports were connected to the pressure transducers on the manometry pump.

2. The pressure outputs were connected to a graphical data display system (Insight Manometry System, Sandhill Scientific, USA).

3. The catheter was flushed with distilled water to ensure that there were no air bubbles within the catheter.

\section{Procedure}

1. The catheter was inserted through the anesthetized nare into the esophagus and stomach while the patient sipped water through a straw. The patient laid down supine on the examination bed with their head angled up $30^{\circ}$ from horizontal.

2. The catheter was flushed with water.

3. Three electromyogram electrodes were attached to the anterior aspect of the patient's neck.

4. The pressure tracings on the graphical display were checked to ensure that the catheter was properly placed within the stomach. The catheter was adjusted as required and taped in place.

5. Several minutes were allowed to elapse until the baseline readings were stable.

6. LES pressure was measured by the resting pull-through technique in $0.5 \mathrm{~cm}$ increments until four perfusion ports had been pulled through the LES sequentially.

7. Lead number 3 was reintroduced into the LES and the patient was given five sips of water at $5 \mathrm{~mL}$ each to assess LES relaxation.

8. The catheter was then repositioned so that the most distal lead was $2 \mathrm{~cm}$ to $3 \mathrm{~cm}$ above the upper border of the LES.

9. The esophageal body study was carried out by performing 10 wet swallows of water, using $5 \mathrm{~mL}$ sips of water.

10. The adhesive tape was removed and the catheter was withdrawn and unplugged from the perfusion pump. 


\section{Catheter cleaning}

1. Tape residue was removed from the catheter using an alcohol-based cleaner.

2. All perfusion ports were flushed with detergent and water.

3. The probe was washed in hot water with Cidezyme (Johnson \& Johnson Inc, USA) detergent.

4. Perfusion ports were flushed with compressed air and the catheter was allowed to air-dry.

5. The catheter was sent for gas sterilization.

\section{Data analysis}

The BioView Analysis software package (Sandhill Scientific, USA) was used with the WP method. The clinical record was edited by the motility nurse before physician review. LES resting pressures, LES relaxations and analysis of esophageal body contractions were performed using visual markers manually placed on the graphical display. The computer program generated pressure estimates, which were incorporated into a written report.

\section{APPENDIX 2 - ESOPHAGEAL MANOMETRY STUDY: HRM METHOD}

For the HRM studies, the ManoScan 360 high resolution esophageal manometry system (Sierra Scientific, USA) was used.

\section{Preprocedural assessment}

Each subject underwent a brief clinical interview and taught about the procedure. Informed consent was obtained. One nostril was anesthetized using Xylocaine 2\% jelly.

\section{Equipment set-up}

1. The ManoScan acquisition program was used. Patient demographic data were entered into the software database.

2. The Sanitary Catheter Sheath (Mui Scientific, Canada) was inserted over the catheter.

3. The catheter was placed in the calibration enclosure to perform the calibration step (at $0 \mathrm{mmHg}$ and $100 \mathrm{mmHg}$ ).

\section{Procedure}

1. The catheter was inserted through the anesthetized nare into the esophagus until the distal end of the catheter was resting in the proximal stomach. The catheter was then taped to the nose.

2. Several minutes were allowed to elapse to provide a stable baseline measurement.

3. The cricopharyngeus and basal resting LES pressure measurements were obtained while the patient refrained from swallowing.

4. Ten wet swallows were then obtained with $5 \mathrm{~mL}$ of water administered into the mouth via a syringe.

5. After the 10th successful wet swallow, the catheter was removed and a thermal compensation step was performed.

\section{Cleaning}

1. The catheter was unplugged from the control box.
2. The protective sheath was removed. Air was insufflated into the removed sheath with a bulb syringe to ensure sheath integrity.

3. The catheter was given a surface clean with alcohol, treated with talc and placed in a protective case for storage.

\section{Data analysis}

The ManoView analysis software package (Sierra Scientific, USA) was used with the high resolution method. The record was edited by the motility nurse before physician review. The data were first corrected for thermal sensitivity using an internal compensation function. The spatial markers for the upper esophageal sphincter, and the upper and lower boundaries of the LES were adjusted manually on the graphical display. A specialized window was used to determine the pressure inversion point. The software automatically placed markers at the beginning peak and at the end of each esophageal peristaltic contraction wave. Each swallow was reviewed to ensure that the marker was placed in an accurate position. Adjustments were made as required. The software automatically assessed the LES residual pressure in each swallow measurement frame using the eSleeve function. The accuracy of the eSleeve placement is reviewed and adjusted as necessary.

\section{REFERENCES}

1. Pandolfino JE, Kahrilas PJ, for the American Gastroenterology Association. American Gastroenterology Association medical position statement: Clinical use of esophageal manometry. Gastroenterology 2005;128:207-8.

2. Murray JA, Clouse RE, Conklin JL. Components of the standard oesophageal manometry. Neurogastroenterol Motil 2003;15: 591-606.

3. Fox MR, Bredenoord AJ. Oesophageal high-resolution manometry: Moving from research into clinical practice. Gut 2008; 57:405-23.

4. Ghosh SK, Pandolfino JE, Zhang Q, Jarosz A, Shah N, Kahrilas PJ. Quantifying esophageal peristalsis with high-resolution manometry: A study of 75 asymptomatic volunteers. Am J Physiol Gastrointest Liver Physiol 2006;290:G988-97.

5. Fox M, Hebbard G, Janiak T, et al. High-resolution manometry predicts the success of osophageal bolus transport and identifies clinically important abnormalities not detected by conventional manometry. Neurogastroenterol Motil 2004;16:533-42.

6. Sierra Scientific Instruments. ManoScan 360 product information. $<$ http://www.sierrainst.com/products-ManoScanSystem.php> (Version current at February 22, 2008).

7. Walamies MA. Perception of esophageal manometry. Dis Esophagus 2002;15:46-9.

8. Reiner BI, Siegel EL, Hooper FJ, Pomerantz S, Dahlke A, Rallis D. Radiologists productivity in the interpretation of CT scans: A comparison of PACS with conventional film. AJR Am J Roentgenol 2001;176:861-4.

9. Bredenoord AJ, Weusten BL, Timmer R, Smout AJ. Sleeve sensor versus high-resolution manometry for the detection of transient lower esophageal sphincter relaxations. Am J Physiol Gastrointest Liver Physiol 2005;288:GI190-4.

10. Malhi-Chowla N, Achem SR, Stark ME, DeVault KR. Manometry of the upper esophageal sphincter and pharynx is not useful in unselected patients referred for esophageal testing. Am J Gastroenterol 2000;95:1417-21.

11. Bredenoord AJ, Weusten BL, Carmagnola S, Smout AJ. Doublepeaked high-pressure zone at the esophagogastric junction in controls and in patients with a hiatus hernia: A study using high-resolution manometry. Dig Dis Sci 2004:49:1128-35.

12. Castell DO. Historical perspectives and current use of esophageal manometry. In: Castell DO, Diederich LL, Castell JA. Esophageal Motility and $\mathrm{pH}$ Testing, 3rd Edn. Highlands Ranch: Sandhill Scientific, 2000:1-7. 


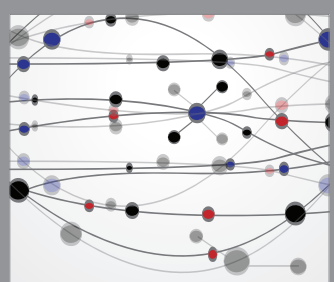

The Scientific World Journal
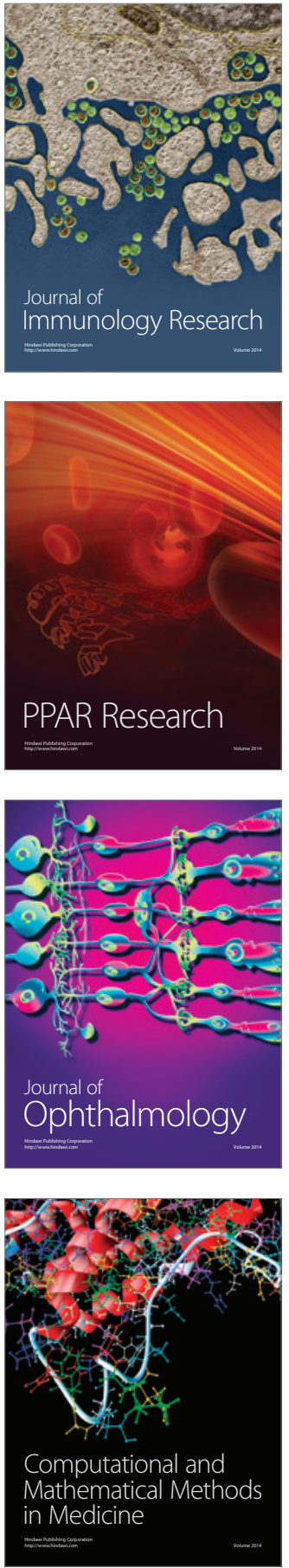

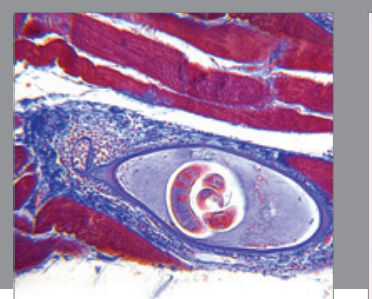

Gastroenterology Research and Practice

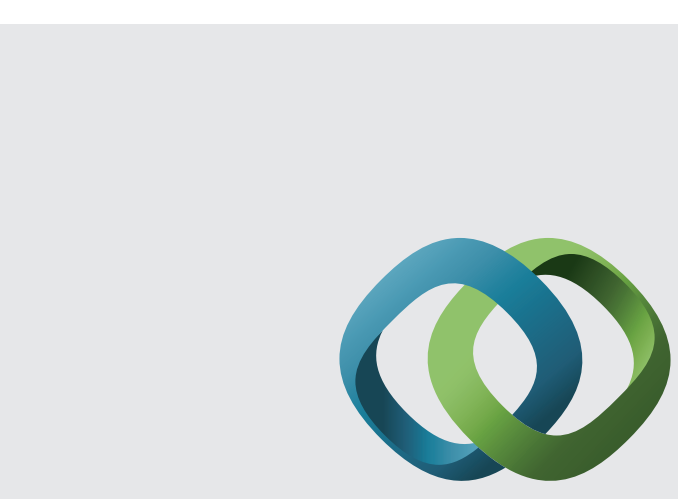

\section{Hindawi}

Submit your manuscripts at

http://www.hindawi.com
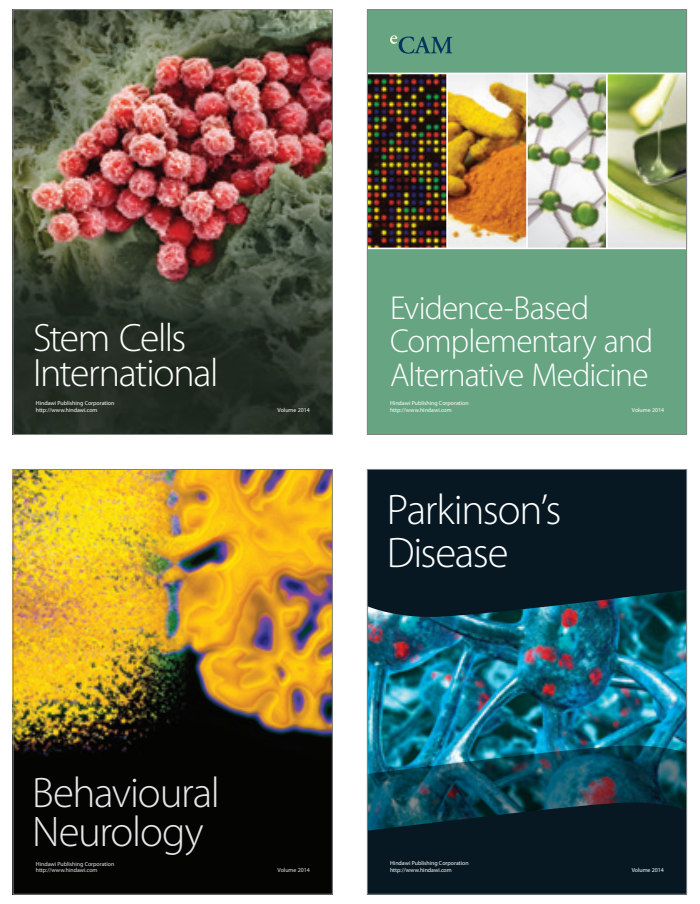
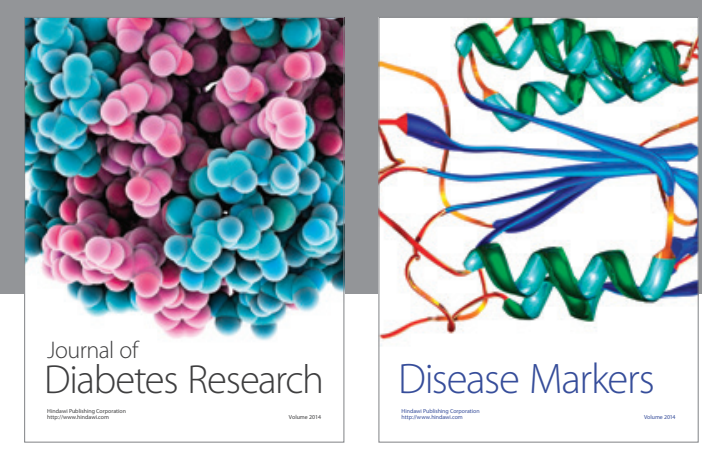

Disease Markers
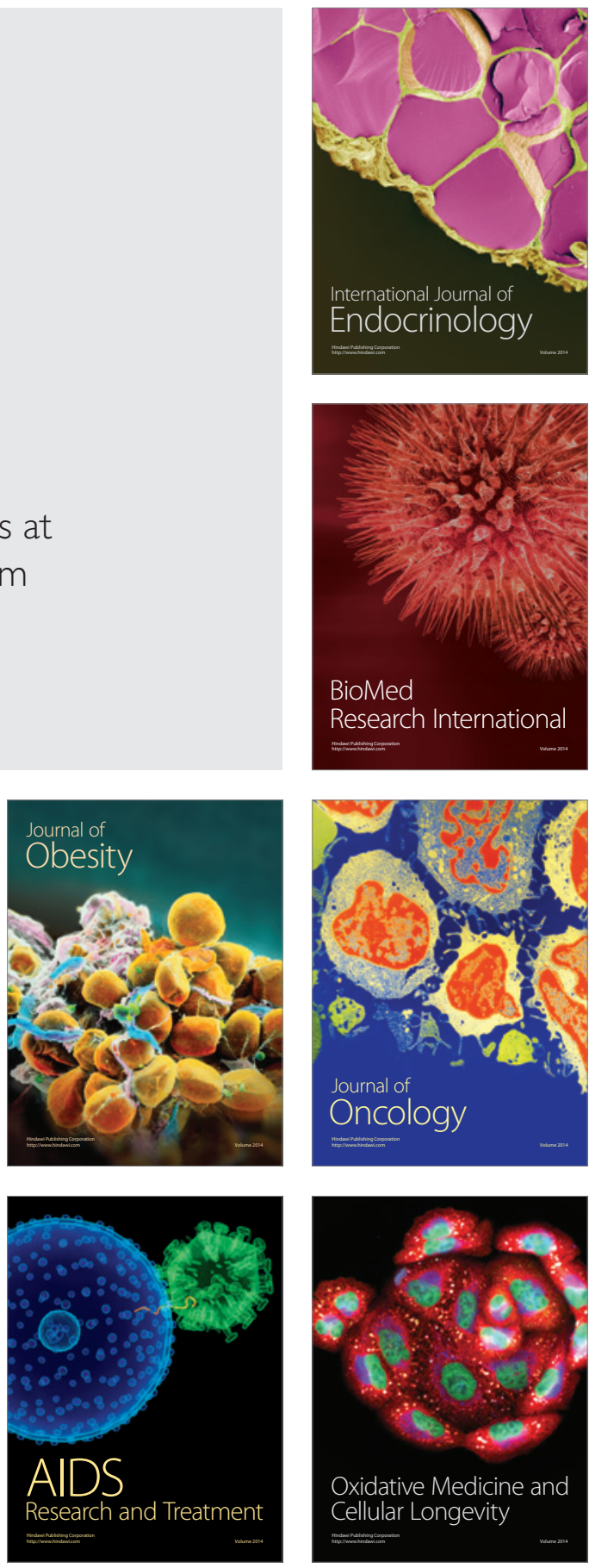